\title{
Making Public Media Personal: Nostalgia and Reminiscence in the Office
}

\author{
Paul André ${ }^{1,2}$, Abigail Sellen ${ }^{2}$, m.c. schraefel ${ }^{1}$, and Ken Wood ${ }^{2}$ \\ ${ }^{1}$ Electronics and Computer Science \\ University of Southampton, UK \\ \{pa2,mc\}@ecs.soton.ac.uk \\ ${ }^{2}$ Microsoft Research \\ Cambridge, UK \\ \{asellen,krw\}@microsoft.com
}

\begin{abstract}
In this paper we explore the notion of creating personally evocative collections of content from publicly available material. Compared to the personal media that we look at, reminisce over, or personalise our offices with, public media offers the potential for a different type of nostalgia, signifiers of an era such as entertainment, products, or fashions. Reminiscence from public media may be particularly valuable in the workplace, where existing practices of office personalisation bring benefits, but also concerns in terms of privacy and disclosing too much of one's identity. The use of filtered public media may mitigate concerns over privacy, while providing similar benefits in terms of reminiscence, improving mood, and developing identity. After preliminary explorations of content and form, we developed a two-screen ambient display that cycled through 500 images automatically retrieved based on four simple user questions. We ran a two-week trial of the display with six users. We present qualitative results of the trial from which we see that it is possible to bring the delight associated with personal content into the workplace, while being mindful of issues of appropriateness and privacy. Images of locations from childhood were particularly evocative for all participants, while simple objects such as stickers, music, or boardgames were more varied across participants. We discuss a number of avenues for future work in the workplace and beyond: improving the chance of an evocative moment, capturing the mundane, and the crowdsourcing of nostalgia.
\end{abstract}

Keywords: reminiscence, nostalgia, identity, privacy, social engagement, workplace

\section{INTRODUCTION}

This project began with a citrus fruit. Peeling a tangerine at home one day, my father remarked how the smell of the peel was oddly nostalgic, evoking memories of his childhood when his mother would regularly buy tangerines. The pleasure experienced in that moment is one of the many benefits of reminiscence and nostalgia, including improving mood and cognition, developing identity and self-worth, and maintaining social bonds (Bohlmeijer et al., 2003; Bluck and Alea, 2009; Webster and McCall, 1999; Wong and Watt, 1991).

Although mundane objects such as the tangerine, or Proust's madeleine cake (1913), can be evocative, the field of Human-Computer Interaction has tended to study and design for reminiscence linked to personal media such as photos and videos that we create or amass ourselves (Peesapati et al., 2010a; Petrelli et al., 2009; Stevens et al., 2003). This project asks a different question. Rather than our digital, personal collections, can we create personally evocative collections of content from public archives? Mining the vast amount of public content on the Web may open up untapped potential for connections to our past. We are thinking here not just of media created by others, but a huge array of materials which are both the by-products and signifiers of everyday life, such as advertisements, news stories, products, music, film posters, and so on.

A second benefit to public media is that there are situations in which there might be complicated

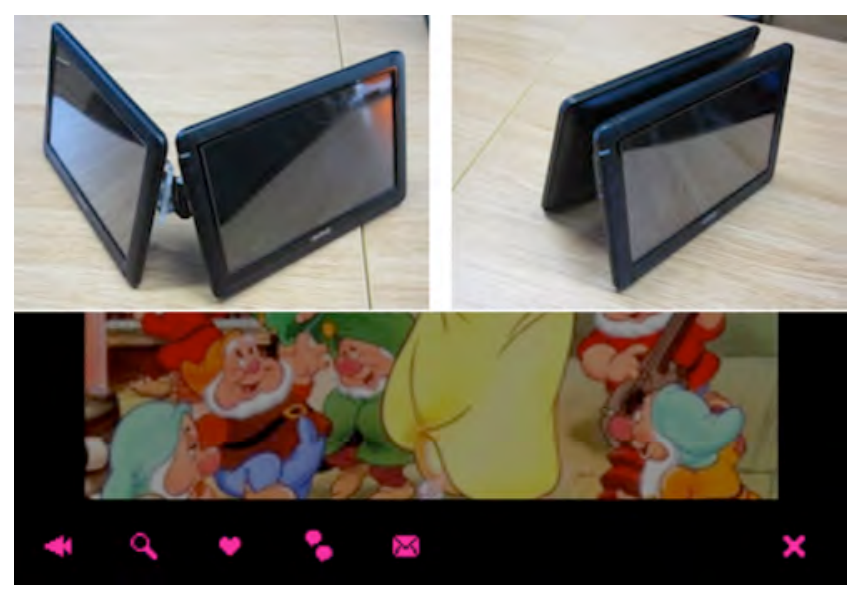

Figure 1. Top: Device to display tailored public content. Two touchscreens, hinged to allow change in configuration. Below: Menu bar after touching the screen to pause. 
issues of privacy or propriety around displaying things that are personal, but where reminiscence and all the benefits it brings are valuable. The workplace is a case in point. We bring personal objects into the workplace to remind us of loved ones or past experiences, and help otherwise sterile spaces reflect those who inhabit them (Tian and Belk, 2005). Members of work groups allowed to display self-identity in such a way have been shown to be more satisfied and productive (Sundstrom and Altman, 1989). However, there exist concerns with privacy, and of self-revelation and vulnerability in choosing items to display (Tian and Belk, 2005).

Additionally, public artefacts used at work may not only be relevant to an individual choosing them for themselves, but may trigger recollections in others who see them, and offer an opportunity for social interaction that would otherwise not be exposed with strictly personal mementos.

Taken together then, the workplace seems an ideal context within which to explore the potential for creating personal archives from impersonal content. Public content may mitigate the concerns over privacy, while providing similar benefits to personal objects in the workplace. In order to explore these issues, our aim was to use a "technology probe" approach (Hutchinson et al., 2003). The focus here was not on the design of a particular technological device, but to test out a protoype concept in situ, allowing us to understand the potential value and reaction to public content for personal association.

In summary, this paper addresses the research question of whether impersonal media gathered from the web can deliver value for people in the workplace in terms of reminiscence and evocation of the past, as well as other benefits seen in the literature such as helping people to bolster or broadcast their identity, or provoking social interaction. Our contribution lies in understanding the potential for public media for reminiscence, and in addressing this issue we hope to point to new kinds of workplace technologies that support a broader range of human values, and broaden the design space for creating systems that are personally evocative.

\section{RELATED WORK}

\subsection{The Human in the Workplace}

Computer science has been characterized by some as "computational Taylorism"-overly task- and efficiency-focused, especially in the workplace (Sengers, 2003). Human-Computer Interaction $(\mathrm{HCl})$ has seen a movement to address a broad range of human values and experience (Gaver, 2002; Blythe et al. 2003), and other fields have long considered the workplace a fertile ground for these human-centered investigations. Who we are is defined by our thoughts and-in many senses of the word-possessions (Belk, 1988). Tian and Belk (2005) discuss possessions in the workplace as part of a personal disclosure to invite interpersonal contact, for self-reflection, or as a reminder of identity (that may otherwise go unspoken at work). Such workplace decoration has been shown not only to have positive benefits associated with affectionate memories of loved ones, but also to improve productivity (Donald, 1994; Sundstrom and Altman, 1989).

However, as the boundaries between home and work blur (Nippert-Eng, 1996), there are concerns over appropriateness and privacy of personal items in the workplace: vulnerability (worry over how items will be interpreted; the process of revealing personal information revealing tender emotions; how "not to reveal everything"; general concerns that home life should be kept at home), and fitting in with organisational norms (Tian and Belk, 2005). To capitalise on the potential benefits of personalising our workspaces, personally tailored public media may provide one way to mitigate such privacy concerns.

\subsection{Reminiscence}

Research has shown that the most frequently observed objects in the office are those that inspire reminiscence, evoking recollections of previous events (Tian and Belk, 2005). Reminiscence, as a form of autobiographical memory, has further been shown to help maintain (or update) a sense of identity over time, and memory retrieval is used in developing, maintaining, and enhancing social bonds for conversation (Bluck and Alea, 2009). Other functions and benefits have also been explored: problem solving, improving mood, and reducing boredom (Webster and McCall, 1999). Reminiscence therapy is used in dementia care, discussing the past with tangible prompts in order to improve well-being and reduce care-giver strain (Woods et al., 2005).

In terms of what we remember, and from what period, there is evidence that the ages of ten to thirty are especially evocative - the so-called 'reminiscence bump' (Rubin et al., 1998). Different elicitation techniques have shown the prevalence of different topics of memories (Elnick, 1999), split between family or relationships and external historical events. Recent work in $\mathrm{HCl}$ to understand what people would like to remember of their past has also shown a desire to capture broader aspects of the world and society (Petrelli et al., 2009). We may be able to explore these cultural aspects through public media. 
Within $\mathrm{HCl}$, memory has been explored within the lifelogging movement, though it has also been noted that reminiscence is a relatively unexplored area (Sellen and Whittaker, 2010). Pensieve (Peesapati et al., 2010a) explores reminiscence through e-mailing previously created social media content, or text prompts about common life experiences. The prompts that triggered most responses were 'things' such as entertainment, appearance and food. Prompts regarding people, family especially, also featured highly. A project to create 'the Living Memory Box' (Stevens et al., 2003) found that people wanted to remove the effort from collecting and revisiting memories, and bring the interaction away from the PC.

In summary, personally evocative objects in the workplace may trigger a number of benefits associated with reminiscence. In exploring the potential for automatically tailoring public content to be personally evocative, work described above has shown we should consider public media to draw on 'things', events and broader aspects of society, that a device should not require personal interaction for creation, and should be separate from the PC. In the following section, we describe preliminary explorations to further explore design issues.

\section{PRELIMINARY EXPLORATIONS}

Before we address questions of value through the use of impersonal media in the workplace, we present the details of a "technology probe" (Hutchinson et al., 2003) we developed to better understand the attributes of this kind of interaction. We had two main considerations for the probe: 1) what content should be used and how it should be tailored to the user, and 2) what form or interaction techniques should be used to present that content. We explored these issues in two small-scale preliminary investigations and a pilot study that influenced our final design. All participants were students or researchers in university or industry.

How do people define their past? We wanted to gain an insight into what type of events people consider important or defining in their lives to guide the selection of content for our device. We asked six participants how they might describe their past to someone else, by asking them to sketch out timelines of their lives. Places were deemed as important: houses and cities lived in, schools attended, or holiday destinations. Two participants also described cultural milestones: the first issue of Wired magazine, or a particular book being released. Three participants listed different interests or hobbies involved in at different stages in their lives. In discussion, participants often had people in mind when writing their timeline, but were reluctant to put that very personal content into a public sphere.
What publicly accessible media is evocative? We asked three participants key questions about their life: what year they were born, what city they were born in, a school they attended, a holiday destination, and some hobbies they had. Based on the previous investigation and related work (Elnick, 1999; Peesapati et al., 2010a; Petrelli et al., 2009), we chose a number of potentially evocative themes and media (e.g., popular films, television shows, image search results of school, images related to hobbies), and automatically populated a brief slideshow of images.

A one-hour session with each participant identified what type of content was considered evocative, and from what periods of participants' lives those moments were drawn. Cartoons, music, images of local cities, fashions of an era all inspired stories, while some of the content we had thought may be of interest, such as news stories from an era, or maps of an area, were not considered evocative. Perhaps unsurprisingly, the non-personal images of hobbies were also considered too far removed from personal experience to be of interest. Audio was discussed, but was thought to be too intrusive in a workplace. The earlier in life the memories were from, the more fond the association, in keeping with the 'reminiscence bump' (Rubin et al., 1998) in the literature. This suggests that in order to tailor content to a user, we should use the early period of their lives for both general cultural content, as well as specific content local to them (e.g., a photo of the area they grew up in).

Form and Interaction. Previous work in creating and curating an archive of memory (Stevens et al., 2003) has found that participants wished to bring the interaction away from the PC, and similar to Overbeeke (2004), we consider the physicality of the product an integral part of its emotional appeal and potential success. Thus, we wished to use a dedicated physical device to deliver the content. Two participants undertook a one week trial with two different hardware designs: ambient-a background display (photo frame) that continuously shows media, and user-initiated-a device that sits closed and is opened to reveal content.

The user-initiated device was initially seen as novel and interesting. There was an expectation of something interesting or relevant in the content, though this occurred perhaps only $5 \%$ of the times the device was opened. For this reason, the first couple of days the participant opened and closed it a few times each session to run through a series of images, but due to the infrequent positive affect, use quickly became much more limited. The photo frame was looked at more favourably, "nice to have somewhere to focus other than work," and the participant felt that a 'pull' technology would be "quickly forgotten about", and other forms of 'push' 
technology, such as through e-mail, "would be punished as it intrudes on my workflow."

Building on the findings of evocative topics from related work, we found that 'cultural' topics such as entertainment and fashion are evocative, as well as local (geographic) content. In terms of the physical device, the unintrusiveness of the ambient display was seen as a positive feature, and important in a work environment. We present the final content and hardware decisions in the following section.

\section{FINAL DESIGN}

\subsection{Content (Scraping)}

From related work (Elnick, 1999; Peesapati et al., 2010a; Petrelli et al., 2009) and our preliminary investigations we identified thirteen topics of potential relevance, listed in Table 1. Ultimately, we were interested in a number of images of each topic: either directly scraped from a website, or using a seed term to submit to an image search engine. Certain topics had 'definitive' lists we could use as seeds, such as the Top 10 films or music albums for specific years. Other categories had fan or enthusiast webpages, such as scans of catalogues from the 60s, or Flickr groups dedicated to 70 s fashions. For the remaining categories, we simply submitted search queries to image search engines (e.g., Google, Bing, Flickr). After scraping images for all the categories (using custom Python scripts, with BeautifulSoup and mechanize), we had a database of around 25,000 images, indexed by category, year or decade, and country (US or UK).

To retrieve images of a location (e.g., a town lived in), we used a geocoding API and calculated a $10 \mathrm{~km}$ bounding circle around that location. Those co-ordinates were submitted to Panoramio, a service with geotagged photos, to acquire a number of images taken around that area. Google Streetview images were also used.

\subsection{Content (Filtering)}

As we saw in the pilot studies, and from the reminiscence bump in the literature (Rubin et al., 1998), memories from earlier years are more powerful than other periods of one's life. Based on a few simple questions, we filtered the information to be most relevant to a person. The questions were: year of birth, two streets lived at, two schools attended, and two holiday destinations. The year of birth gives us an index into the database (e.g., year born $+7=$ the start of a time period likely to hold fond memories). The names of streets or schools are used to retrieve images from services with geotagged photos, such as Panoramio, or used in an image search.

\begin{tabular}{|c|c|c|}
\hline Boardgames & Disney Films & Toys \\
\hline Cartoons & Fashion & TV Shows \\
\hline Catalog Pages & Food & (local content) \\
\hline Children's Films & Music & Geotagged \\
\hline Commercials & Products & Streetview \\
\hline
\end{tabular}

Table 1. From preliminary investigations, we identified a number of topics of publicly available content to filter for personal meaning.

We posited that although all categories may contain evocative images, we would be able to better filter certain categories to improve the likelihood of a personally relevant image. For instance, location images are local and may have a higher chance of being recognised than music or films from an era. We used around 100 locationbased images, with 400 images of other categories, resulting in a corpus of 500 images for each participant.

\subsection{Device}

Having refined our decision to use an ambient display, we wanted an object that was more than just another monitor or photoframe. To emphasize this difference, to enhance the social aspect of the device, and to enable different configurations for different offices, we chose to hinge two 7" touchscreens (Mimo UM-720s external USB monitors), as in Fig. 1. We gave participants a laptop to drive the screens (hidden under the desk), and the screens were placed where the participants wished.

Similar to a screensaver or photoframe, the software randomly displays an image from the corpus of 500 , refreshing once a minute. (We posited that this time period was short enough to retain interest if the image was irrelevant, but long enough to not cause distraction through quickly cycling images.) The same image appears simultaneously on both hinged screens.

Touching either screen pauses the slideshow, and a menu bar appears at the bottom of the screen, showing a number of basic functions a user can perform. From left to right (as shown in Fig. 1): back: display previous image; more info: display the domain the image was retrieved from and why (e.g. "Disney films"); favourite: mark the image as a personal favourite for later discussion; chat: mark the image as having spurred discussion; e-mail: send the URL of the original image to the user; close: return to slideshow.

\section{METHOD}

To explore our questions around the value and experience of our public media device, we ran an in-situ deployment in a workplace setting. Six 


\begin{tabular}{|c|c|c|c|}
\hline Pseudonym & Sex & Age & Role \\
\hline Bill & Male & 35 & Contractor \\
\hline David & Male & 48 & Manager \\
\hline Harry & Male & 45 & Developer \\
\hline Janet & Female & 32 & Researcher \\
\hline Kate & Female & 27 & Administrator \\
\hline Ted & Male & 25 & Intern \\
\hline
\end{tabular}

Table 2. Characteristics of participants.

participants of varying ages, roles and backgrounds used the devices for two weeks (see Table 2). The devices had a corpus of 500 images, and changed images every minute.

At deployment, participants were informed of the purpose of the device, and that the images on the device had been automatically tailored to them based on their answers to the questions posed. It was explained that not all images were likely to be personally evocative, but that we would be trying to understand which images were, how often that occurred, and the experience of use. During those two weeks, participants could interact with the device to mark images as a personal favourite, as having inspired discussion, or to flag for other reasons. Participants were interviewed once a week.

Two weeks, as it turned out, provided a long enough time to understand both the strengths and weaknesses of deployed systems, including pointing to ways in which the devices could be more successfully deployed for longer periods of time in future.

Most participants had grown up and lived in the United Kingdom, though one had grown up in North America and moved to the UK. Participants had varying roles and tenure within the organization, from an intern to a group manager. The offices of our participants reflected both this difference in role, and in personality (see Fig. 2). Kate's office, for example, had a number of personal photographs, Harry's had a variety of personal objects, whereas Ted's and Janet's had limited personal decoration. David placed the screens back-to-back in his office, whereas others (in differently configured offices) tended to place the screens so that one was facing them, and the other facing toward visitors.

\section{FINDINGS \& DISCUSSION}

\subsection{General Comments}

Initial expectations differed between perceiving the device as a personal and powerful object, or assuming most images would not be relevant and

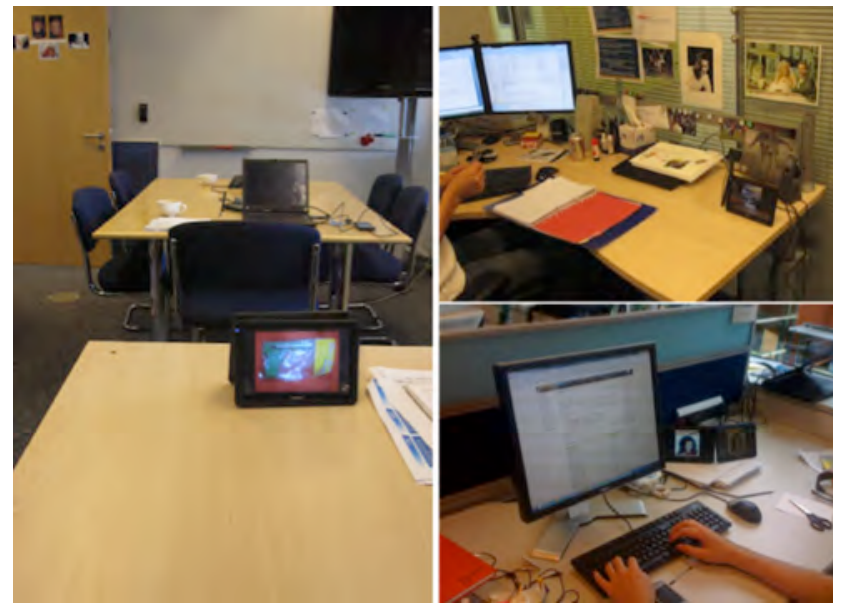

Figure 2. Deployment of screens in three participants' working environments.

being surprised when one was. By the second week, participants seemed to calibrate their expectations, and the device was generally well received:

It's worked well for those little moments of reminiscence. During my day I would look across and think 'oh yeah Top Cat', or [location], thinking about my family going to watch the fireworks. I would have these little moments of reminiscence, even for the deep ones, then go back to whatever I was doing. I enjoyed that. (David)

\subsubsection{Comparison to Other Reminiscing}

One aspect of interest was how this device was perceived to be different to other ways in which reminiscing occurs. There is a sense that this work tries to recreate a spontaneous and serendipitous moment of reminiscence. We wondered whether having a device intentionally meant for this purpose would somehow change or alter the experience for participants.

\section{I don't think [having a specific device] cheapens the experience, it just increases the possibility of it happening. You might be randomly reading a newspaper and then think 'oh I remember that tv show', but I don't see why that's any better than having it pushed at you. (David)}

Bill talked about previous instances of remembering something, and then intentionally searching to satisfy that. Janet noted that though this device helps spark a memory or association, it doesn't help you develop that further; it doesn't allow the exploration that Bill talks about. A way to engage in a dialogue with the device was desired, although such an extended and involved interaction was seen as not suitable for a work environment.

\subsubsection{Ambient Presentation Liked: Unintrusive}

Participants were unanimously in favour of the ambient nature of the display: 
Good because quite unintrusive. Also something I can dip in and out of, so sometimes it's running for a while and I'll see it on out of the corner of my eye. So has that sort of peripheral trigger that draws me in. I can go to it, rather than it being completely in my face. (Bill)

We had considered attempting to instigate reminiscence, or asking a question to prompt deeper reflection (as in Pensieve (Peesapati et al., 2010a)), but participants found value in "the convenience" of 'sparked' reminiscence, and "... the fact I could just look at it when I had time, no onus on the user."

There were two ways to retrieve more information about a displayed image from the device: the 'more information' button, and the 'e-mail me' button. The information button was used extensively by all participants, mostly to check if the person had remembered or reasoned correctly about why the image was being presented, or to enquire further when something that was not recognized at all was displayed. The e-mail button was used infrequently, around once a week by each participant, although there were a small number of occasions when a participant would initiate their own web search, finding out more information about a film, or watching clips of a cartoon that had sparked a fond childhood memory.

\subsubsection{Workplace Appropriate: Impersonal and Ambient}

We focused on a workplace setting with public content after considering the advantages and the concerns around personal objects in the office, and our own desire to consider supporting human value oriented artefacts in the workplace. In discussions with others prior to the trial, there had been a worry that even this public content in the workplace could be seen as either revealing too much information, distracting, or inappropriate.

The content was considered impersonal enough not to be a privacy issue (as we elaborate in the Identity section). As Ted said, "some stuff could be really relevant, and some stuff might not be, who else is going to know which is which." Harry commented on the workplace setting, "I really like it... openly celebrating... spread of ages and backgrounds."

Having such a device was not seen as inappropriate for the workplace (in terms of a comparison to other personal objects), and not a distraction from work. The ambient nature of the device, as well as the chance of both relevant and irrelevant content, helped to minimize this concern.

I'm aware that I am at work as well, so I think the kind of stream for work is fine, since that's kind of quite low ... low impact... and it's no more distraction than the odd social e-mail at work that kind of thing. (Bill)

\subsection{Reminiscence and Nostalgia}

\subsubsection{Relevance of Content}

Trying to assess the success of using filtered public content to provide a personally relevant set of images using quantitative measures is hard (and perhaps not useful): participants used the 'favourite' button for many different purposes, and subjective reporting of percentage of relevant content ranged from $5-40 \%$ across participants. More enlightening are the comments in interviews, highlighting differences in the number of relevant images and the experiences evoked.

There's a real variety, a couple of them struck me... a lot of the stuff just goes by. (Bill)

There was a range. Some that I weren't quite sure why [they came up]. A lot of things that were interesting, There were several times when something came up that I hadn't thought of in years, a game I used to play as a kid, so that was good. (David)

\subsubsection{Different Types of Relevance: General Era,} Location, Specific Event

Location images were particularly evocative for all participants, from general recollection or stories of an area, to specific memories of experiences (see Harry's example below). It may be the case that the more local something is to you, the more evocative it is. It may be easier to draw on a memory of a specific place rather than a more abstract or generic image. For example, the following image reminded Harry of family visits to a local town:
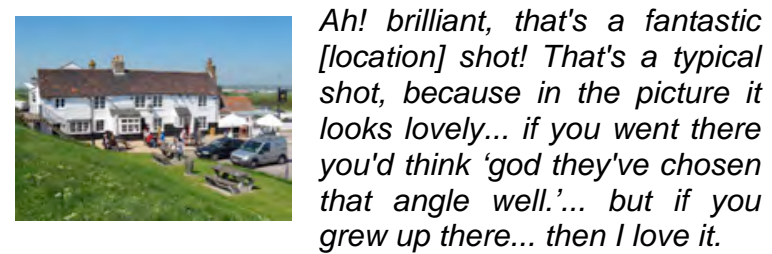

Other categories of image were favoured differently between participants, and evoked different types of memory. For instance, a product image reminded Janet of the general era of the 80 s:

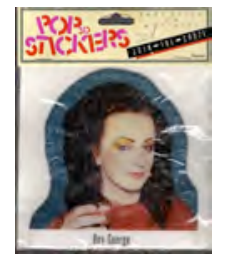

I like this... the whole concept of stickers and pop [music], the kind of thing you'd get with [magazine] or something. This is exactly the kind of thing you'd do as a child, not just music, but the type of thing you'd do when you were 10, which is to have stickers.

And a film poster reminded Ted of a specific event: 


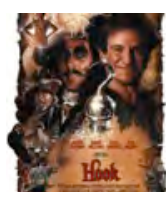

This is the first ever VHS video I ever bought. There's nothing special about [the film itself] really, but I remember buying it with my own money.

Some of these might be seen as nostalgia for an era (Janet's thoughts about stickers in the 1980s, for instance), whereas others are reminiscing about a specific time or event in the participant's past (the act of buying a video).

\subsubsection{Depth of Affect}

Of the images that did elicit a fond thought or memory, there were differences in the perceived depth of that experience as Kate discusses:

[The] initial emotional attachment isn't there as much, doesn't come flooding back as something you've actively done, or taken, or been given. It's more like a reminder.

Other participants did have the occasional powerful memory 'flooding back,' or "hit" as Kate termed it. These differences were explained in terms of, say, seeing an image of a film poster and remembering the film (a shallow effect), or at other times, it involved remembering more of the context around the object-the cinema one went to, the people one saw it with (a richer affect). David, for example, discusses a particularly evocative picture of a boardgame:

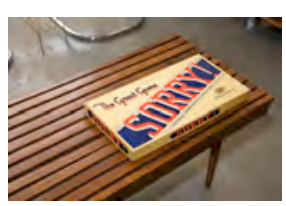

I hadn't thought about that game in ages. When I was little, my brother and I used to play that. My uncle had that game, we found it at his place. I hadn't thought about it in 30 years or so, and there it was.

Participants varied in the depth of their response to the images. Three of the participants encountered a number of more powerful memories, while three did not have the same depth of experience. In those cases, Janet summarizes:

It's made me remember, has brought back a few memories. Quite shallow, but has brought back memories.

\subsubsection{Irrelevant Images}

Of the images that were not seen as relevant or evocative, the general consensus was that "because of the ambient-ness, you're not performing an action to look at it, it just kind of floats by, and I think it doesn't really matter."

There were a small number of images that were not deemed as personally relevant, but were marked as a 'favourite' for another reason. These reasons included aesthetics, raising other thoughts or reflections (comparing 60s fashion images to what people wear today), or were at first misinterpreted as being relevant, but on closer inspection were found to be something different (an image that looked like actors from a favourite film, or a duck pond imagined to be from a specific location).

Occasionally an image with no direct personal association would spark something tangential and more personally evocative. Harry describes an image from a film that he had not seen:

It's another one of those ones where it's a miss... so that's absolutely not from when I grew up, but it's so evocative of... [late 70s], I had a lot of friends who looked exactly like that, so that seemed a very good evocation of [that era].

\subsubsection{Comparison to Personal Objects}

Three participants had personal objects (mostly pictures) in their office. Commenting on the static nature of those images, "I don't get bored of them, I don't look at them as often because they're still, but when I do look at them, they still bring back the same big smile." Similarly, David said of personal photos in the office: "Sometimes those fade into the background very quickly... but that's not true with the changing display."

Personal photos are on one hand representative of a specific point in time, "that was all our friends, that night, I can even remember what we ate," but if it's somebody close to you that you continue to interact with, "a picture from the past might spark new memories of that person." The dynamic images, however, are potentially "more of a generalization of a poignant time," though that in itself may be enough to bring a smile.

\subsubsection{Familiarity and Reminiscence over Time}

In the majority of cases, repeated images that originally evoked a positive reaction were seen favourably, but over time having less of an impact. Janet, however, commented on some of the initially irrelevant images actually having an opposite effect:

Repetition made me think about it more carefully. The first time cued it up... and the second time around it made me think more closely about my own memories.

Bill raises a thoughtful question about our ability to reminisce over time:

I wonder what... the extent of reminiscence is. Can you keep on doing it forever? Is it a finite resource? Once you've gone through all these... once you've gone through every single thing you saw and did and touched as a child... (Bill)

Is there a store of emotion, and can we exhaust it? On a small scale we saw something to that effect during the trial, "It got less interesting over time, because I did end up seeing the same images 
relatively often. And when I saw... it didn't have the same impact, but I still enjoyed seeing it again." Other participants expressed similar sentiments, that they didn't think they would get bored of it long term, but that would be dependent on the content being refreshed.

\subsection{Identity and Social Interaction}

In addition to reminiscence, we also considered other effects of personal objects in the workplace such as what they say to others about one's personal identity and how they might provoke social interaction.

\subsubsection{Identity}

In the first days of the trial, Kate explained, "Other people that came into my office were like 'oh why have you got them up there,' people kept thinking it was my pictures I put up there." This highlights the fact that accountability is an important issue. If people can't be held accountable for selecting the content, then this changes how it is perceived.

There was a difference in the way that the object was perceived individually, as David discusses:

Depending on how good a job this does, it's as if somebody else placed a personally relevant object.

and how Janet thought others might view it:

It's ambiguous enough that the images might be disconnected from me anyway, and where it is personal, it's only personal to the extent that it'll still be common to an awful lot of people, so I didn't feel like it was bound up in my identity.

We had wanted to achieve this mix between relevance for the individual, but common enough that there were no worries of self-revelation and privacy.

Relevant images were viewed positively, while irrelevant ones tended to 'float' past. One participant, however, had a very different perception of the non-personally relevant content, tied to the concept of identity. As Harry explains (light-heartedly but genuinely):

I find it insulting when they're badly wrong. I find the ones that are a miss easy to ignore, and some of them are really intriguing, but the ones that you think 'god this has got me wrong' are really annoying. ... When you're told this should be one of your memories... There was a sense of intent... and that is annoying, when they're so wrong.

Unlike other participants that were either a little bemused, or let the irrelevant media fade into the background, Harry viewed the device, despite the ambient nature, as telling him what to remember- what his identity should be, in some sense. This was partially because of high initial expectations, and over the two weeks Harry explained that the device faded into the background and he became happier with it, his ire dissipated, and positive experiences stood out more.

\subsubsection{Social Interaction}

We wondered whether our device would spark conversations, or lead colleagues to share insights about their lives outside of work, despite the fact that the images shown might not be shared cultural references.

Conversations relating to the content (rather than just the novelty of the device) were rare, happening an average of once per participant in the two-week trial. Where conversations did occur, it was a mix of the participant pulling someone else in, or a colleague initiating discussion.

Perception of content, too, could have played a part, as Janet discussed:

\section{If l'd chosen a photo, it makes sense to come in and say 'oh what's that a photo of', but because it's being streamed from the web, ... less of an expectation that I know what it is.}

We had initially considered the potential of the device to provide an opportunity for conversation, or ice-breaking between visitors or new colleagues. Harry discusses a previous example of choosing content for this purpose:

I had a picture of [TV test card] on the wall. We did a bunch of projects with technical broadcast people and I found that was an image every single person had an anecdote about, so having that image on my whiteboard was really useful. So when a new [visitor] would walk into my office they'd go 'oooh' and tell me something, so it was a really nice icebreaker.

As Harry did here, in future work we may wish to consider explicitly finding common ground.

\section{CONCLUSIONS}

In this study we have explored the vast amount of user-uploaded and public content on the web as a museum from which we can curate a collection of personally meaningful materials. We contribute a number of findings to reminiscence work, and to attributes of human values in the workplace.

In contrast to previous systems that have pushed content for reminiscence, via e-mail (Peesapati et al., 2010a), we have shown that an ambient display is valued for reminiscence. The first steps at coarse-grained tailoring of public material to a personally evocative set have shown value in 
(varying depths) of reminiscence, resulting in pleasurable moments of nostalgia. Participants in previous work (Petrelli et al., 2009; Peesapati et al., 2010a) have expressed a desire to capture broader aspects of culture and society, and we have found that simple objects from childhood can evoke rich memories. Such objects, however, vary across participants, from music, to board games, to toys. Location images, on the other hand, were found to be universally evocative. Unlike Peesapati (2010b), however, maps did not elicit any positive memories, perhaps because they were ambiently displayed (in our system), rather than actively engaged with (in theirs). Both studies found Google Street View images evocative.

The automatic selection of images led to two identity-related implications. One is that the owners of the devices themselves were led to reflect on what the device was saying about them, and to frequently question that association. Second, because they had not selected the images, this altered the extent to which they judged it to broadcast their identity to others, and indeed for others to make that judgment. So, in a sense, taking control away from the owner in terms of content selection significantly alters the value of this device in relation to identity, in contrast to personally chosen content to broadcast one's identity (Belk, 1988; Tian and Belk, 2005).

Limitations. While we did see memories and stories emerge for positive affect, our findings highlight a number of issues to be addressed in further consideration of generic reminiscence devices. After two weeks participants began to grow tired of seeing the same images appear, and though some categories could be refreshed, others, such as the local images that are rarer, could not. The proportion of images that were personally evocative was also low, and though participants felt that the ambient nature of the device mitigated any problems with irrelevant images, it is important to explore both a higher volume of content in the future, and tailoring that content to provide a higher likelihood of personal association.

The workplace is a potentially problematic design space for such work: we saw a tension between brief and delightful moments of reminiscence, and a desire to take those brief moments further, to allow for direct interaction and further exploration. However, such in-depth exploration was not necessarily seen as appropriate in a work environment. Longitudinal studies of different devices in different contexts (different types of work environment, and in the home) are necessary to explore the potential value of reminiscence from all types of (digital) media.
The system and the ensuing field trial we have described is clearly only a first step in exploring a new approach to creating personally relevant collections from public media. Its use in a workplace setting at this point has shown itself mainly to spark curiosity, reflection and occasional moments of delight. Proving deeper value and benefits beyond this remains for future work.

\section{FUTURE WORK}

We discuss three possibilities for capturing more (and more evocative) content, and two broader avenues for reminiscence from public media.

Capturing the Local (and Mundane). Local content was the only content topic that every participant mentioned as evocative. One implication is that these collections would be more evocative if they contained 'local' content from key places in people's lives, or ordinary things that serve as context for an evocative place and era: news stories from one's home town, prices of things from a corner shop, specific games played either at home or in the playground, slang, pictures or audio clips from local personalities, and so on. Though hard to scrape currently from the web, these provide the potential for evocative experiences.

More Directed Refinement. We had deliberately chosen a minimalist approach using a few key dates and places. But, drawing on Janet and Bill's comments about intentionally searching for nostalgia, or engaging in a dialogue with a system, we could envision a more elaborate seeding process than the four simple questions we asked our participants. A guided but exploratory search through possible media and interests (e.g., are videogames or sports relevant?) might allow both an engaging experience as well as providing rich detail for seeding a reminiscence device.

In addition, the device could use images that have been marked as "favourites" as the basis on which to go and search for more images with a similar theme. Thus, the device could be more interactive, constructing its database much more "on the fly."

Social Interaction. We saw a limited number of discussions arising from content. Future work could investigate methods to maximise the chance of two people seeing a shared cultural touchstone.

Clinical Value. Reminiscence therapy has been used for some time in dementia and other forms of cognitive impairment (Woods et al., 2005). Currently, the process of gathering these materials centers on trawling through personal archives, which can be both arduous and intrusive. We are in discussion with a clinical psychologist to see if this 
approach might offer new ways of producing relevant materials.

Crowdsourced Nostalgia. Websites such as Historypin ask users to upload historic photos and tag them with geographic co-ordinates, allowing one to 'walk through the past.' Other sites encourage users to list their top ten cartoons, YouTube videos, or other type of media. Exploring this concept, we could crowdsource the elicitation of potentially evocative childhood milestones, extending to seemingly mundane content. With a large enough global population, we could even use the corpus to interrogate by demographic, e.g. what might a person born in India in 1960 consider a childhood memory, compared to someone born in Brazil in 1984?

Reminiscence is a powerful human act, not just able to provide a brief smile or moment of delight, but value in terms of maintaining a sense of identity and developing social bonds. People use personal objects in the workplace to provide these benefits, but those objects come with privacy and propriety concerns. This paper presents the possibility of mitigating those concerns through reminiscence from public media, and our findings offer a basis for exploring both personal and work-related value in the future.

\section{ACKNOWLEDGMENTS}

Our thanks to participants, anonymous reviewers, Siân Lindley and members of the Socio-Digital Systems group for helpful discussions, and John Helmes for help with hardware design.

\section{REFERENCES}

Belk, R. W. (1988) Possessions and the Extended Self. Journal of Consumer Research, 15, 139-168

Bluck, S., \& Alea, N. (2009) Thinking and talking about the past: Why remember? Applied Cognitive Science, 23. 1089-1104.

Blythe, M.A., Overbeeke, K., Monk, A.F., \& Wright, P.C. (eds.) (2003). Funology: From Usability to Enjoyment. Kluwer.

Bohlmeijer, E., Smit, F., \& Cuijpers, P. (2003) Effects of reminiscence and life review on late-life depression: a meta-analysis. Int. J. of Geriatric Psychiatry, 18.

Donald, I. (1994) Management and change in office environments. J. of Env. Psychology, 14, 21-30.
Elnick, A. B. (1999) Benchmark Memories in Adulthood: Central Domains and Predictors of Their Frequency. J. of Adult Development 6(1), 45-59.

Gaver, B. (2002) Provocative Awareness. Comput. Supported Coop. Work 11, 3, 475-493.

Hutchinson, H., et al. (2003) Technology probes: inspiring design for and with families. Proc. CHI 2003. 17-24.

Nippert-Eng, C. E. (1996) Home and work: negotiating boundaries through everyday life. University of Chicago Press.

Overbeeke, K., et al. (2003) Let's make things engaging. In Funology: From Usability to Enjoyment. Kluwer.

Peesapati, S. T., Schwanda, V., Schultz, J., Lepage, M., Jeong, S., \& Cosley, D. (2010a) Pensieve: supporting everyday reminiscence. Proc. CHI 2010.

Peesapati, S. T., Schwanda, V., Schultz, J., and Cosley. D. (2010b). Triggering memories with online maps. Proc. ASIS\&T 2010.

Petrelli, D., van den Hoven, E., \& Whittaker, S. (2009) Making history: intentional capture of future memories. Proc. CHI 2009.

Proust, M. (1913). In Search of Lost Time. Translated by Scott-Moncrieff C.K. et al. 1992. London: Chatto and Windus.

Rubin, D. C., Rahhal, T. A., \& Poon, L. W. (1998) Things learned in early adulthood are remembered best. Memory \& Cognition, 26, 3-19.

Sellen, A. J. \& Whittaker, S. (2010) Beyond total capture: a constructive critique of lifelogging. Commun. ACM 53, 5, 70-77.

Sengers, P. (2003) The engineering of experience. In Funology: From Usability to Enjoyment. Kluwer.

Stevens, M., Abowd, G., Truong, K., \& Vollmer, F. (2003) Getting into the Living Memory Box: Family archives \& holistic design. Pers. Ubiq. Comput. 7, 3-4.

Sundstrom E. \& Altman, I. (1989) Physical environments and work-group effectiveness. Research in Organizational Behaviors 11, 175-209.

Tian, K. \& Belk, R. W. (2005) Extended Self and Possessions in the Workplace, Journal of Consumer Research, 32, 2, 297-310.

Webster, J. D. \& M. E. McCall. (1999) Reminiscence Functions Across Adulthood: A Replication and Extension. J. of Adult Dev. 6, 1.

Wong, P. T. P. \& Watt, L. M. (1991) What types of reminiscence are associated with successful aging. Psychology and Aging, 6, 272-279.

Woods B., Spector A.E., Jones C.A., Orrell M., \& Davies S.P. (2005) Reminiscence therapy for dementia. Cochrane Database of Systematic Reviews, 2. 